\title{
In Memoriam: Dr. Hiroshi Hashimoto (1924-2015)
}

\author{
Masaru YAMAMOTO* \\ 1-6-12, Satomachi, Yoshimi, Shimonoseki, Yamaguchi Prefecture, 759-6525, Japan \\ *Corresponding author: qsphn570@ybb.ne.jp
}

Key words: Dr. Hiroshi Hashimoto; memorial; Clunio; mating behavior; isomorphism.

Received: February 2018. Accepted: June 2018.

This paper was presented at the 20 $0^{\text {th }}$ International Symposium on Chironomidae, Trento, Italy, 2-8 July 2017. Session: In Memoriam.

Dr. Hiroshi Hashimoto (Fig. 1), Emeritus Professor of Shizuoka University, passed away on 26 February 2015, at the age of 90 years. Chironomid workers within and beyond Japan must never forget that three entomologists, Drs Masaaki Tokunaga, Hiroshi Hashimoto and Manabu Sasa, have contributed greatly to the progress of chironomid taxonomy, morphology, ecology and public health (Fig. 1).

Dr. Tokunaga was a pioneer of Japanese chironomid studies, and an excellent morphologist and taxonomist of nematoceran Diptera, for examples of Nymphomyiidae, Ceratopogonidae, Tipulidae, Trichoceridae, Psychodidae and Ptyochopteridae.

Dr. Sasa described approximately over 1000 chironomid species from Japan, and supported many young scientists engaged in environmental science and public health in terms of research planning and financial assistance.

Dr. Hiroshi Hashimoto was born on 20 April 1924 in Tokyo. In 1961, he got a doctoral degree from Tokyo University of Education (later renamed Tsukuba University). Still in 1961, he started his career as a scientist at Shimoda Marine Biological Station, which belonged to the Faculty of Science at Tokyo University of Education, where he worked on ecological and taxonomic studies of marine chironomids (Fig. 2). Especially he focused on investigations of tidal rhythms and mating behavior in the genus Clunio Haliday, 1855. In 1968, Hashimoto transferred to Shizuoka University. While continuing the ecological and taxonomic work on

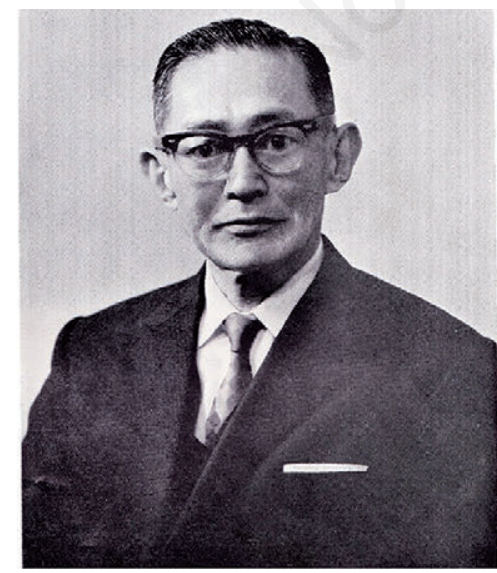

Dr. Masaaki Tokunaga (1903-1998)

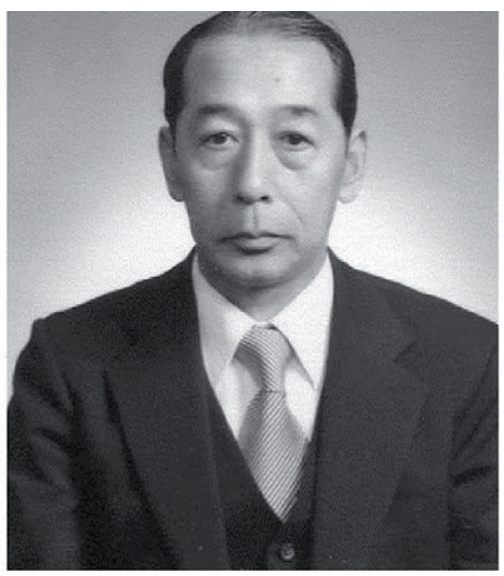

Dr. Hiroshi Hashimoto (1924-2015)

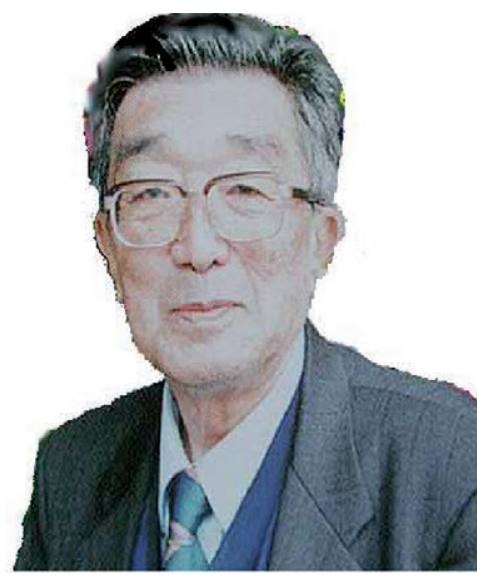

Dr. Manabu Sasa (1924-2006)

Fig. 1. Three leading Japanese chironomid workers to be remembered: Drs Masaaki Tokunaga, Hiroshi Hashimoto and Manabu Sasa. 
marine chironomids, he began to study the fresh-water chironomids and hydroids. He retired from Shizuoka University in 1988 .

Dr. Hashimoto contributed greatly to elucidating the unusual mating behavior of marine chironomids in the genus Clunio, proposed an evolutionary consideration of the phenomenon of sexual isomorphism in Chironomidae, and provided a critical spark to restart the studies of Chironomidae in Japan that have continued until today.

\section{BEHAVIOR OF MARINE CHIRONOMIDS, CLUNIO TSUSHIMENSIS AND C. TAKAHASHII}

Clunio tsushimensis Tokunaga, 1933 and $C$. takahashii Tokunaga, 1938 show quite interesting respective mating behavior. In either species, the female pupae are unable to molt by themselves; instead, a male has to assist by using its legs and the hypopygial gonostyli. In C. tsushimensis, mating is started after parts of the female pupal exuviae are stripped away by the male. The process of female emergence with male assistance in C. tsushimensis is shown in Fig. 3. In contrast, the mating behavior in C. takahashii is very different. Hashimoto (1976, page 399) stated: "In this species, the male often copulates with a female whose anterior half is still lying in the nest case with only the posterior half of the abdomen stripped the pupal skin off."

\section{EVOLUTIONARY CONSIDERATION OF SEXUAL ISOMORPHISM IN CHIRONOMIDAE}

Hashimoto (1962) stated that sexual differentiation in the more "specialized" (i.e., apomorphic) forms among the marine chironomids follows two very different major modes. In the genera Clunio and Pontomyia Edwards,
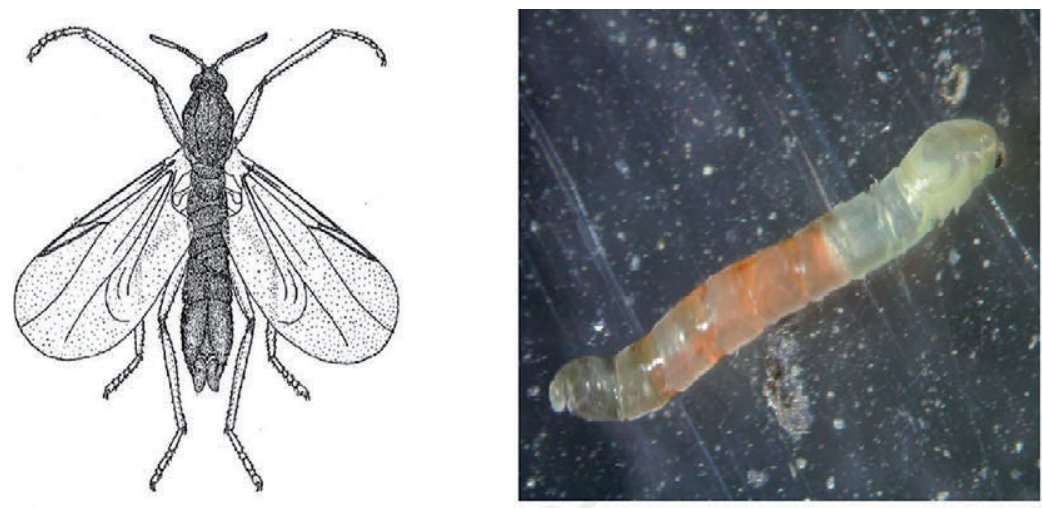

A

B
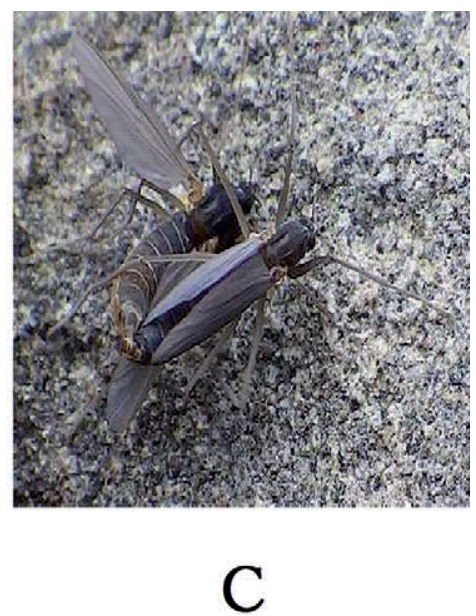

Fig. 2. Marine chironomids. A) Clunio tsushimensis, adult male (after Tokunaga, 1937). B) Pontomyia pacifica, adult female (Courtesy of K. Sugimaru). C) Telmatogeton japonicus, adults in copula (Courtesy of K. Kadoma).

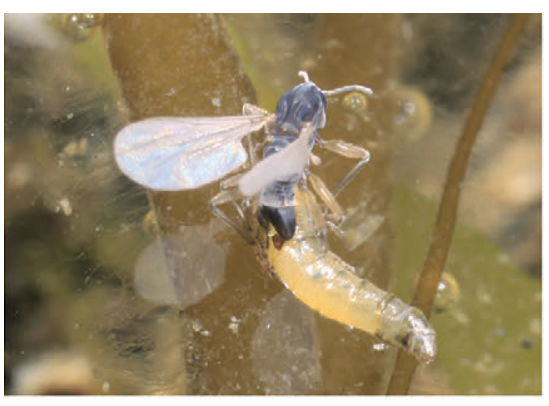

A

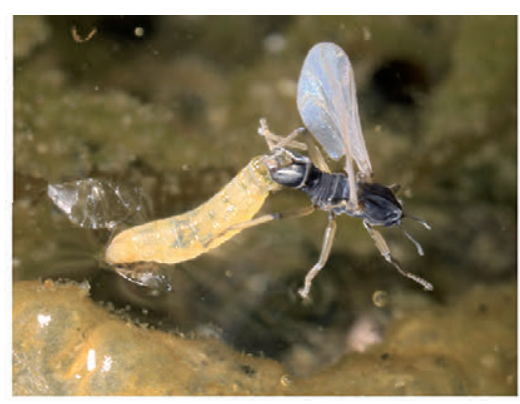

B

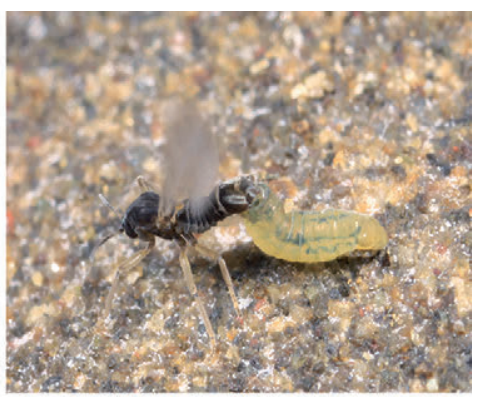

C

Fig. 3. Mating behavior in the genus Clunio. A-C) Female emergence with male assistance in C. tsushimensis (Courtesy of R. Cornette). 
1926, the dimorphism that is common to less specialized marine taxa and the vast majority of non-marine chironomids has been increased extremely, resulting in the adult sexes showing radically different morphology (Fig. 3). In the second mode, which Hashimoto termed isomorphic specialization, the 'normal' sexual differences are considerably reduced, rendering the two sexes almost isomorphic (Fig. 1C). Among marine chironomids this latter phenomenon is known from the genera Telmatogeton Schiner, 1867, Thalassomya Schiner, 1856, Eretmoptera Kellogg, 1900, and Tethymyia Wirth, 1949. It has been found also in some species of Diamesinae and some non-marine Orthocladiinae (Yamamoto, 2006).

Following Hashimoto (1962, page 224), adult sexual isomorphism can be summarized as follows:

- The size of the antennae is alike in the two sexes.

- Plumose setae on the antennae are reduced in both sexes.

- The antennal scapes are almost equal in size in the two sexes.

- The number of antennal flagellomeres is usually the same in both sexes.

- The respective grade of degeneration of the palps, wings, halters and scutellum results in smaller differences between the sexes than in the other genera. On a personal note, it has been quite interesting for

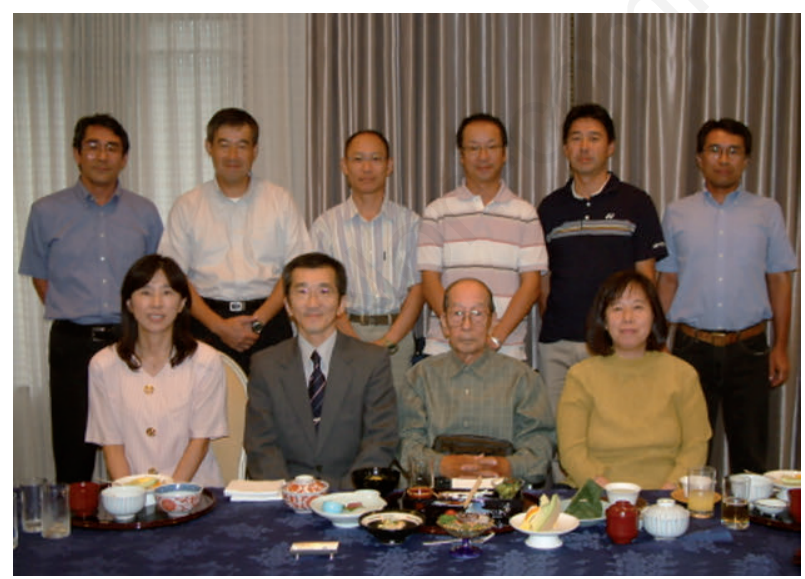

Fig. 4. Dr. Hashimoto and his graduated students on 23 August 2008 in Shizuoka City (Courtesy of H. Niitsuma). me to study this phenomenon throughout the family Chironomidae.

\section{RESTARTING STUDIES OF CHIRONOMIDAE IN JAPAN}

Hashimoto (1977a, 1977b) published two papers in which he commented on the morphological features of adults and larvae in the genus Chironomus Meigen, 1803 for Japanese chironomid workers. Although these papers contain only a few species with brief explanations, they effectively restarted the studies of Chironomidae in Japan that have continued until today.

Dear Dr. Hiroshi Hashimoto, your students (Fig. 4) and successors thank you with heartful gratitude for giving us so invaluable contributions about Chironomidae!

\section{ACKNOWLEDGMENTS}

I wish to express cordial thanks to Dr. R. Cornette (National Institute of Agrobiological Sciences, NARO), K. Sugimaru (Fumakilla Ltd), and Dr. K. Kadoma (Kanagawa Environmental Research Center) for offering me invaluable photos of Clunio tsushimensis and Pontomyia natans. I thank Dr. H. Niitsuma (Shizuoka University) and Dr. S. Kondo (Aichi Prefecture) for valuable information and providing the photograph of Dr. Hashimoto and his students.

\section{REFERENCES}

Hashimoto H, 1962. Ecological significance of the sexual dimorphism in marine chironomids. Sci. Rep. Tokyo Kyoiku Daigaku, Section B 10:221-252.

Hashimoto H, 1976. Non-biting midges of marine habitats (Diptera: Chironomidae), p. 377-414. In: L. Cheng (ed.), Marine insects. North Holland Publishing Company.

Hashimoto H, 1977a. [Japanese Chironomus].[Article in Japanese]. Heredity 31:78-84.

Hashimoto H, 1977b. [Japanese Akamushi (= larvae of Chironomus)].[Article in Japanese]. Heredity 31:76-81.

Tokunaga M, 1937. [Family Chironomidae (1)].[Article in Japanese]. Fauna Nipponica 10. Sanseidou.

Yamamoto M, 2006. [Sexual isomorphism and sexual dimorphism occurring in non-biting midges].[Article in Japanese]. Kontyu to Sizen 41:22-25. 